diagnosis was based on histopathological findings seen in the distal oesophageal mucosa. The diagnosis of $H$. pylori infection was made if rapid urease test and histological examination of gastric biopsies obtained during endoscopy were both positive. All the findings were retrospectively examined. The Statistical Package for the Social Sciences for Windows Release 16.0 was used to analyse the statistical data.

Results Of the 206 children, $70(34.0 \%)$ had GA. H. pylori infection was found in $72(35 \%)$ children. No significant difference was found when the prevalence of $H$. pylori infection in patients with GA (24 of $70,34.3 \%$ ) was compared with that in patients without GA (48 of $136,35.3 \%)$.

Conclusion No evidence has been found in this pediatric study to support the view that there might be an association between $G A$ and $H$. pylori infection.

\section{FOOD ALLERGY - GASTRO-ESOPHAGEAL REFLUX DISEASE ASSOCIATION IN INFANTS}

doi:10.1136/archdischild-2012-302724.0685

C Cazan, L Dobrota, ML Neamtu. Pediatric Clinic Hospital, Lucian Blaga University of Sibiu, Sibiu, Romania

Background Cow's milk allergy is considered to be the first and most common type of allergy during early infancy. Gastroesophageal reflux disease and cow's milk allergy are two different diseases with common clinical features.

The aim of the study was to evaluate the clinical data in relation with gastroesophageal reflux and cow's milk allergy in infants.

Material and Methods The prospective study includes 36 infants aged between 2-6 months who attended at Pediatric Clinic during the year 2011 for the clinical evocative manifestations of gastroesophageal reflux. Study protocol includes: clinical criteria, familial/ personal atopic features, mother diet, duration of breastfeeding, infant formula, esophageal ultrasonographic study, serum specific IgE cow's milk.

Results The clinical presentations of the infants were associated or isolated agitation/irritability, feeding refusal $(p<0.0002)$, poor weight gain $(p<0.0001)$, vomiting, wheezing, apnea and atopic dermatitis. Specific Ig E revealed allergy in 10 cases. The implication of cow's milk allergy was in 10/36 cases (27.7\%). The key elements evocating the link between cow's milk allergy and gastroesophageal reflux were the persistence of symptoms under anti-reflux therapy and the improvement of symptoms under the exclusion of cow's milk. Favorable clinical course, disappearance of symptoms, weight gain under anti-reflux therapy confirmed the gastroesophagial reflux in the other cases. Esophageal ultrasonography was a useful noninvasive test in patients with reflux.

Conclusions Clinical assessment and allergy tests in infants with the suspicion of gastroesophageal reflux revealed the association of these diseases. The concomitant therapy was followed by clinical resolution of symptoms.

\section{NUCLEAR TRANSIT SCINTIGRAPHY (NTS) - AN EVOLVING ROLE FROM DIAGNOSTIC TO MONITORING TOOL IN CHILDREN WITH CHRONIC CONSTIPATION}

doi:10.1136/archdischild-2012-302724.0686

${ }^{1,2,3} \mathrm{Y}$ Y Yik, ${ }^{4} \mathrm{DJ}$ Cook, ${ }^{4} \mathrm{DM}$ Veysey, ${ }^{4} \mathrm{CF}$ Tudball, ${ }^{4} \mathrm{BS}$ King, ${ }^{4} \mathrm{KA}$ Morris, ${ }^{4} \mathrm{TM}$ Cain, ${ }^{3}$ BR Southwell, $2,3,5 \mathrm{JM}$ Hutson. 'Department of General Surgery, Faculty of Medicine, University of Malaya, Kuala Lumpur, Malaysia; '2Department of Paediatrics, University of Melbourne; ${ }^{3}$ Gut Motility and Research Laboratory, Murdoch Children's Research Institute; ${ }^{4}$ Department of Biomedical Imaging; ${ }^{5}$ Department of Urology, Royal Childrens Hospital Melbourne, Melbourne, VIC, Australia

Purpose Nuclear transit scintigraphy (NTS) is a relatively new investigation for children with intractable chronic constipation.
Three patterns of colonic transit were identified: normal, slow and rapid colonic transit. We aimed to determine the use of NTS over the last 12 years at a tertiary institute. We hypothesised that NTS has evolved from a diagnostic to a monitoring tool.

Methods NTS were reviewed retrospectively (1999-2011) and characterized based on 3 different colonic transit patterns with further division into a new/repeat study (Ethics30059A). Statistical analysis was performed with Chi-square test to examine the effect of change; $p<0.05$ considered significant. Transcutaneous electrical stimulation (TES) was introduced to treat slow-transit constipation (STC) since 2006. Hence, we examined the changing role of NTS before and after TES use in STC children.

Results From 1999-2011, there were 955 NTS performed (667 new and 288 repeat studies): normal colonic transit - 133 new and 27 repeat; rapid colonic transit - 190 new and 24 repeat; slow colonic transit - 344 new and 237 repeat studies; with more repeat studies for STC children ( $p<0.0001$, Chi-square). There was an increase of repeat studies from 1999-2005 (15\%) to 2006-2011 (30\%, p<0.0001). Since 2006, 95/237 (40\%) NTS performed were repeat studies to monitor the effects of TES in STC children.

Conclusion NTS has is a useful diagnostic tool and helps to improve management of chronic constipation by guiding therapy, targeting the underlying dysmotility. It also provides objective assessment in monitoring response to therapy/intervention.

\section{ROLE OF INTRAUTERINE CMV INFECTION IN FORMATION OF BILIARY ATRESIA}

doi:10.1136/archdischild-2012-302724.0687

${ }^{1}$ AV Degtyareva, ${ }^{2} E L$ Tumanova, ${ }^{1}$ AA Puchkova, ${ }^{3}$ NV Kulikova. 'Paediatrics, Kulakov Research Centre for Obstetrics, Gynecology and Perinatology; ${ }^{2}$ Pathologicoanatomy, Russian Medical University named after Pyrogov; ${ }^{3}$ Children Surgery, Filatov Children Clinical Hospital N13, Moscow, Russia

Aims To establish the role of congenital virus infection in formation of biliary atresia (BA)

Methods 75 pts age from 1 to 9 months with the following diagnoses: BA - 44, PFIC2-9, Alagille syndrome-9, bile duct cyst -7 , deficiency of a-1-antitrypsin (ZZ-phenotype)-4, perinatal sclerosing cholangitis-2, galactosemia- 1 and one patient had hepatitis as a result of congenital general acute CMV infection. Among common examinations, laboratory tests and instrumental methods, following methods were used: DNA of CMV, HSV1.2, EBV, HBV and RNA of HCV was analyzed by PCR on biopsies of the liver, blood and urine, as well as histological examination of liver biopsy performed.

Results Liver biopsy specimens were CMV DNA positive for the patient with congenital acute CMV infection, for 37 (84\%) pts with $\mathrm{BA}$, for 4 pts with Alagille syndrome, for 3 pts with bile duct cyst and for 1 child with PFIC2. EBV DNA test was positive only for 1 patient with BA and 1 with bile duct cyst. Presences of HSV1.2, HBV DNA and HCV RNA have not been found in all liver biopsy specimens. Blood samples were CMV DNA positive for the patient with congenital acute CMV infection, for $6(14 \%)$ pts with BA. Urine samples were CMV DNA positive for the patient with congenital acute CMV infection, for $7(16 \%)$ pts with BA and for 5 pts with Alagille syndrome.

Conclusion We assume that intrauterine CMV infection may play an important role in pathogenesis of BA.

\section{ARE THE 2009 ESPGHAN/ESPID'S RECOMMENDATIONS IN} ACUTE GASTROENTERITIS USED CORRECTLY?

doi:10.1136/archdischild-2012-302724.0688

${ }^{1} \mathrm{H}$ Antunes, ${ }^{2} \mathrm{D}$ Farinha, ${ }^{3} \mathrm{~V}$ Baptista. 'Gastroenterology, Hepatology and Nutrition Unit, Pediatric Department, Braga Hospital, Life and Health Sciences Research Institute 
(ICVS), School of Health Sciences, University of Minho, ICVS/3B'S - PT Government Associate Laboratory; ' Gastroenterology, Hepatology and Nutrition Unit, Pediatric Department, Braga Hospital; ${ }^{P}$ Pediatric Department, Braga Hospital, Braga, Portugal

Background The ESPGHAN/ESPID acute gastroenteritis (AGE) recommendations management were published in 2009.

Aim Study these recommendations in a tertiary hospital ER during rotavirus (RV) season.

Material and Methods Retrospective, observational and analytical study, from January 1 to April 30, 2010, in younger than 18 years old, admitted at the ER with criteria for AGE $>3$ stools in the last 24 hours).

Results From the 13780 children admitted in ER, 770 had AGE (incidence $5.6 \%$ ). Were male $57.1 \%, 93.5 \%$ came without prior referral and $91.5 \%$ didn't take Oral Rehydration Solution (ORS). Had fever $34.2 \%, 68.7 \%$ vomit and $10.9 \%$ dehydration. At the ER, the ORS was administered in $62.1 \%$. Diagnostic tests were not performed in $63.8 \% ; 4.4 \%$ were admitted at the observations room; $0.3 \%$ at the pediatric department. Age was significantly associated with use of ORS (ORS: $42.84 \pm 45.16$ months vs "no ORS" $87.16 \pm 64.61, p<0,001)$. The ORS was prescribed to $68.2 \%$, "not recommended" drugs in 63 cases and more often in older children ("not

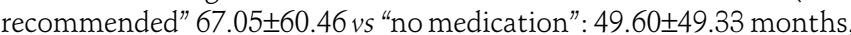
$p=0,038)$. Blood analyses were performed in $6.4 \%$ and in children significantly older (85.57 $\pm 65.62 v s 51.89 \pm 54.49$ months, $p<0,001)$. Similar results were observed for the urine dipstick (85.57 \pm 65.62 vs $54.14 \pm 49.51, p=0,002)$, stool $(85.57 \pm 65.62 v s 28.16 \pm 38.50, p=0,008)$ and stool/blood (85.57 $\pm 65.62 v s 13.45 \pm 13.85, p<0,001)$. At discharge, diet changes were recommended in $37 \%$ children.

Conclusion AGE incidence was 5.6\%. Management was most based on ESPGHAN/ESPID's recommendations. There was still an inappropriate use of drugs and diet changes. The use of ORS before referral to the ER was rare.

\section{LACTOSE HYDROGEN BREATH TEST (LHBT) IN CHILDREN: IS IT A USEFUL TOOL?}

doi:10.1136/archdischild-2012-302724.0689

KM Upatissa, BF Rodrigues, H Patel, S Mahadevan-Bava. Paediatrics, Russells Hall Hospital, Dudley, UK

Children with lactose malabsorption can present with chronic diarrhoea, increased flatulence, abdominal pain or constipation. The simple solution is a trial of Lactose free diet (LFD).

Aim and method: Our aim is to assess the usefulness of LHBT for objective measure of LI and appropriate dietary advice. We retrospectively reviewed 36 children with symptoms of Lactose Intolerance (LI), who underwent LHBT attending the paediatric gastroenterology clinic at RHH from 2009-2011.

Results 36 children (20M:16F) (34 Caucasian) aged 2-17 years were identified. All baseline tests and Coeliac screen were negative. The presenting symptoms: diarrhoea (12), flatulence (14), abdominal pain (10) IBS (2) and constipation (12). 12/36(33\%) were positive (8/12 hydrogen load suggested LI and $4 / 12$ small bowel bacterial growth) LHBT. 5/8 with positive LI, showed marked improvement on LFD. Although $24 / 36$ were negative LHBT, $5 / 24$ started trial of LFD with $3 / 5$ success.

Conclusion LHBT is a simple non invasive and cost effective test that is useful in diagnosing LI in children. It gives objective evidence to parents to commence lactose free diet, thereby avoiding unnecessary omission of milk and dairy-products (19/36 potential cases in our study) that can have detrimental effects on calcium and vitamin $\mathrm{D}$ intake in children.
'V Ismaili-Jaha, ' $\mathrm{M}$ Shala, 'M Azemi, 'T Hoxha, 'M Avdiu, ${ }^{2} \mathrm{~S}$ Spahiu. 'Pediatric Gastroenterology; ' ${ }^{2}$ niversity Clinical Centre of Kosova, Pediatric Clinic, Prishtina, Kosovo

Material and methodology Authors have studied the seasonal distribution of the gastroenteritis caused by rotavirus. The study was prospective and was conducted at the Department of Pediatric Gastroenterology of the University Clinical Center of Kosova, during one year. Testing of the stool was performed using agglutination test with the sensitivity and specify of around $96 \%$.

Results Of 1011 children aged 0-5 years, hospitalized at the Department of Pediatric Gastroenterology due to gastroenteritis, 116 had rotavirus infection. At the admission all children were with diarrhea, $97.41 \%$ had vomiting and $43.96 \%$ had fewer. $70.7 \%$ of patients had moderate dehydration and $29.3 \%$ severe dehydration All patients in the study were intravenously rehydrated. All patients healed with no sequels. The seasonality of the disease was distinctive and had two peaks - first in late winter/early spring (January-16, February-9, March-9 and second in late summer/early autumn) August-11, September-20 and October-14

Conclusion Two peaks seasonality late winter/early spring and late summer/early autumn of the rotavirus infection reflects the difference in the wealth of the population in Kosova, with first peak in winter, similar to the one in the developed countries and the second peak in summer, similar to the one in non-developed countries.

\section{CLINICO-EPIDEMIOLOGICAL CHARACTERISTICS OF PEDIATRIC ESOPHAGITIS IN SOUTHERN IRAN: A SINGLE CENTER EXPERIENCE}

doi:10.1136/archdischild-2012-302724.0691

M Zahmatkeshan, K Najib, B Geramizadeh, E Fallahzadeh, M Haghighat, MH Imanieh. Shiraz University of Medical Sciences, Shiraz, Iran

Objectives To determine the clinico-epidemiological characteristics of pediatric esophagitis in southern Iran.

Methods A cross-sectional study was conducted during a 4-year period from 2005 to 2009 in Nemazee hospital, a tertiary healthcare center in Shiraz, southern Iran. We consecutively included all the pediatric patients ( $<18$ years) who underwent endoscopy in our center and had pathology-confirmed diagnosis of esophagitis. Data regarding the patients' demographic characteristics, comorbidities, and clinical findings were recorded using a questionnaire. All the patients underwent upper GI endoscopy and biopsy of the esophagus and the findings were recorded in the questionnaire.

Results We studied 125 children among whom there were 61 (48.8\%) girls and 64 (51.2\%) boys with mean age of $6.6 \pm 5.5$ years. Intractable vomiting was the prominent symptom in our series being reported by 75 (60\%) patients followed by fever in $35(28 \%)$. Erythema (33.6\%), esophageal ulcer (11.2\%), and whitish patch $(8.0 \%)$ were the most common endoscopic findings while reflux esophagitis $(32.8 \%)$, chronic $(6.4 \%)$ and acute esophagitis $(5.6 \%)$, and candida esophagitis (5.6\%) were the most common histological diagnoses. Just $1(0.8 \%)$ patient was diagnosed as having eosinophilic esophagitis, aspergillosis, and graft versus host disease.

Conclusion Reflux is the most common cause of esophagitis in the pediatric population of southern Iran. Despite previous reports the prevalence of eosinophilic esophagitis is far less than estimated while the prevalence of opportunistic infections is higher secondary to post liver transplantation immunosuppression.

\section{INCREASING THE FREQUENCY OF EOSINOPHILIC ESOPHAGITIS IN CHILDREN: IS IT REAL?}

